\title{
The Effect of English Language and Literature on the Development of Students' Language Ability
}

\author{
Yan Xiong \\ School of Humanities, Jiangxi University of Traditional Chinese Medicine, Nanchang, 330006, China
}

Keywords: English language and literature; language development.

\begin{abstract}
Living in a social environment, each of us needs to communicate with others. The quality of a person's language is directly related to the establishment of his contacts and to the development of his space. Just as an ancient Chinese saying goes, "Good words warm people in winter, and the evil language hurts people in June." Students need the ability to communicate with others, need to learn the mysteries of speaking, and need to improve language skills. College and university is an ivory tower for teaching and educating people, and teachers also develop students' language skills as a teaching task. In the process of learning language, it is necessary to improve language ability by learning literature. English language and literature have the effect of cultivating students' language ability. This paper analyzes the necessity of improving students' English language ability, discusses the rationality of students' learning English language and literature, and puts forward the effect of English language and literature on the cultivation of students' language ability according to the current situation of contemporary college English language and literature.
\end{abstract}

\section{Introduction}

In the wave of globalization, the links between countries are gradually strengthened. English as an international language is playing an increasingly important role. Language promotes economic and cultural exchanges, promotes economic development, and advances human civilization. People-to-people communication is inseparable from language, communication effects and language skills are closely related, English language and literature are rich in language expression, beautiful vocabulary, sentences, and expression of different local customs, language style, English language Literature, like Chinese ancient literature and modern and contemporary literature, is an embodiment of excellent foreign culture. It has been accumulated for thousands of years, and the author's excellent language skills have been vividly demonstrated. In universities, students of the Faculty of Arts are more demanding on language skills than other students, and they must be improved. English is a required course for each major. It is necessary for English majors to learn English language and literature. However, for non-English majors, few schools set up courses on English language and literature in English teaching, neglecting English language. The importance of literature to students (especially the students of liberal arts colleges).

\section{Necessary Conditions for Improving Students' Language Ability}

\subsection{Situation settings}

In the process of learning a language, we need situations to practice in order to effectively improve our language skills. For example, in the process of learning Chinese, we need to listen to others and communicate with others in the general context of China in order to continue to exercise our language skills, master basic vocabulary and sentence components, and gradually improve our daily communication. The ability to use language. At the same time, in the classroom, the teacher can also give guidance to the student's speech and emphasize the tone and tone of the communication. Students can appreciate the subtlety of language step by step. In addition, during reading, students 
can apply the learned vocabulary and sentences to reading. Through reading, they can understand the beauty of language, the richness of language, and the subtlety of language expression. Only in the situation can students master language skills and improve their language skills.

\subsection{Strong interest}

Interest is the best teacher. People can only continuously improve their ability if they have enough interest in things. Some people may be interested in literature. Then he will use his time under class to read literary works, master idioms in his works, and continue to accumulate beautiful sentences and acquire the writing skills. If a person is interested in English, he will be under the class. To watch American dramas, improve their listening abilities, familiarize them with the way they speak, and understand the etiquette of foreigners. He will often read foreign literary works, continuously improve his English level, improve his ability to respond to vocabulary and sentences, and make flexible use of them. The ability of vocabulary to improve language skills.

\subsection{Application of language}

The most important thing in learning a language is the application. To apply the theory to practice, you must integrate language into your life. The improvement of language can not be separated from listening, speaking, reading and writing. Then the application of language must also be reflected in these four links. People can only improve their ability to speak only when they open their mouths and communicate in a certain language in daily communication. People can improve their listening ability to a certain language only by listening and listening frequently; Consolidate language knowledge and improve one's ability to use language flexibly; people can only practice language and write in order to strengthen their mastery of language and acquire language skills.

\subsection{Teachers' input}

Language learning is inseparable from the teacher's guidance. Although language can be integrated into life to improve language skills, teachers' guidance can enable students to master language mastery in the direction of refinement and quality, and teachers' mastery of language-related knowledge. Has an important role for students. Teachers can grasp the details that people ignore when they use language, analyze the language, analyze the polysemy of words, use syntax, explain the flexible use of expressions, and use language skills. The usual language practice pays attention to details, pay attention to the accumulation of language, mastery of skills.

It can be seen from the above that the improvement of language ability needs to be applied to life in a situation with a strong interest in language and under the guidance of a teacher. While English language and literature can provide reading situations and teacher guidance, students can meet the needs of language use. Literary stories can also improve students' interests. Therefore, putting English language and literature into teaching will inevitably improve students' language ability.

\section{The Status Quo of English Language and Literature in Colleges and Universities}

It is understood that there are no more than 80 schools that offer English language and literature courses in non-English majors in universities in China, accounting for less than $4 \%$ of the total. Among these schools, there is an imperfection in the setting of English language and literature courses; The students' English proficiency level shows that 70\% of the students pass the CET4, 40\% of the students pass the CET6, and no more than 3\% (excluding English majors) actively read English literary works.

\subsection{Lack of understanding of the importance of English language and literature}

At university, English is one of the compulsory subjects. For English majors, English teaching is perfect, and students learn English language and literature. However, for non-English majors, many English teachers are required to pass the final grade. Students do not attach importance to the role of English language and literature for non-English-speaking students. In classroom teaching, teachers 
often focus on teaching materials for students to learn. Students are not required to read extracurricular reading of excellent works of English language and literature. For the students of the Faculty of Arts, when setting up teaching subjects, subject leaders also neglected the connection between English language and literature and Chinese literature, ignoring the importance of English language and literature for improving students' language proficiency.

\subsection{Lack of English language teaching}

The lack of teaching of English language and literature is not only reflected in the teachers' lack of attention, but also reflected in the weak teaching ability of teachers' English literary works. Although the teachers of the Faculty of Arts have specialized foreign literature teachers, their teaching style is inevitably narrated by Chinese textbooks. Many languages lose their original "flavors" in the process of translation, and many teachers follow the first reading. The way to explain it again is to explain the background of the work, character introduction, and ideological content. There are fewer languages for words, sentences, and techniques. In addition, English teachers are very professional in English and can appreciate foreign works. The profound meaning of words and words, but under the education philosophy of "Quality First", teachers rarely teach English language literature.

\subsection{Irrational English language and literature teaching materials for non-English majors}

Although there are courses in English language and literature for many colleges and universities, there is no careful consideration in the selection of teaching materials. Although there are foreign literary works in the selected textbooks, the works in the textbooks are only excerpts, breaking the students' works. The overall perception, and for some non-foreign literature students, they sometimes lack the teaching of English language and literature, and sometimes set up related courses, but due to the emphasis on the professional knowledge and lead to less English language and literature. In addition, some majors of the Faculty of Literature will set up English language and literature courses according to the requirements, but they have not been combined with the actual situation, resulting in a large number of textbooks ordered. Many students received many textbooks in this language before the semester, but only one of them was learned at the end of the semester.

\subsection{Students lack reading on English language and literature}

Students of the Faculty of Arts need to consolidate their professional knowledge by reading English language and literature works, broaden their horizons, and improve their literary accomplishments. However, many students tend to study in accordance with the requirements of teachers. Teachers do not invest time and energy when they do not ask for it. Therefore, in some schools where English language and literature are not valued, it is difficult for students to consciously read English literary works. The writing ideas and language cultivation provided by the English language and literature works should be deeply understood by the students of the Faculty of Arts. However, due to the students' lack of attention and laziness, they cannot obtain knowledge to improve their language skills.

\section{The Effect of English Language and Literature on the Development of Students' Language Ability}

\subsection{Improve students' mastery of Basic English knowledge}

English and Chinese are the specific expressions of language. Learning Chinese versions of English language and literature can improve one's literary accomplishment and learn the language arts of foreign countries, while studying untranslated English language and literary works can directly improve students' English language skills. The mastery of knowledge and basic knowledge of English refer to the learning of vocabulary, grammar, and sentences. At the university level, English is a required course. Students need to take English exams during the freshman and sophomore years. In addition, students also need to take the English exams for grades 4 and 6, so learning English is 
necessary. Vocabulary is the basic element of language composition. In the process of reading English language and literature works, students can see various vocabulary. If it is a vocabulary that has just been learned recently, this reading will deepen the memory of the word if it is a strange word. Students can also learn new words by reading them. Continuous reading can increase students' vocabulary. In addition, the formation of language can not be separated from grammar, in the process of reading English language and literature works, students can gradually accumulate sentence patterns, and apply to the usual exchanges, writing, improve their own language organization. At the same time, there are many famous quotes and graceful sentences in the works. They can be applied to writing and communication and can express their literary qualities.

\subsection{Improve students' communication skills}

Whether it is Chinese, English, or any other language, it was originally invented for interpersonal communication. English language and literature has a history of hundreds of years or even thousands of years, fully demonstrating the times of various periods, some of which are even more Directly describing people's ways of communication and speaking at the time, meetings held by upper classes, and the behavior of people depicted at the party, these can all be expressed in the works. Students can learn Western communication methods based on these scenes. Improve your communication skills. In addition, if the students insist on reading English language and literature works, their English level can also be improved. If they need to communicate with foreigners in school or in the usual part-time process, students' good English can be strengthened with foreign friends. Exchanges to improve students' communication skills. At the same time, some students may travel abroad during winter and summer vacations, and can communicate fluently through the reading of English language and literature.

\subsection{Enrich students' language expression}

The language expression of students embodies the level of language ability. In ordinary life, different objects, different occasions, and different literary works require different ways of expression. Students must master different language expressions before they can live and work. Flexible use of learning. In English language and literature works, many articles have an ironic expression, such as "Red and Black." Some articles use narrative expressions, such as "Royal Rowland's" "John Christopher", and some use black humor. The way to express, such as "Slaughterhouse Five," students can learn how to use expressions in their studies and life. In addition, by reading English language and literature works, students can also learn about the celebrities of many foreign celebrities, enrich their own language expressions, understand cultural common sense, and understand new ideas and things. In the ordinary life, these contents will affect students' language expression.

\subsection{Expand students' knowledge}

Different literary works reflect the cultural background and customs of different countries. By reading English language and literature works, students can understand the customs, culture, and time background of foreign countries and expand their horizons. For example, students can learn about the helplessness and darkness of the human nature of the lower classes of the capitalist European people in the 19th century by reading Oliver Twist. Reading Hamlet can help students understand that it is a reflection of the history of the eighth century in Denmark. British social reality. Through reading, students can understand the blood and changes of capitalist society, expand their knowledge, and come to terms with language expressions.

\section{Conclusion}

University is a transition period from a student to a social person. Compared with other professions, society has a higher requirement for the language ability of the students of the Faculty of Arts. Colleges and universities need to integrate English language and literature to improve students' 
language ability according to the actual situation of the university. In teaching, students' language skills are continuously improved.

\section{References}

[1] Zhou Ying. An Analysis of the Role of English Language and Literature in the Development of Students' Language Ability, Journal of Changjiang Series, 2016(34).

[2] Lu Hua. The Effect of English Language and Literature on the Development of Students' Language Ability, English for Campus, 2016(12).

[3] You Xiangwen. The Role of English Language and Literature in the Development of Students' Language Ability, Science \& Technology Innovation Review, 2011(16).

[4] Chen Ruojing. The Role of English Language and Literature in Improving Students' Language Application Ability, English Place, 2016(3).

[5] Li Jing. Influence of English Language and Literature on the Function of College Students' Header Competence, Contemporary Education Practice and Teaching Research: Electronic Journal, 2015(7). 